\title{
HUBUNGAN PIJAT OKSITOSIN DENGAN KECUKUPAN ASI DI WILAYAH KERJA PUSKESMAS KARANGDOWO
}

\author{
Sri Kandini, Endang Suwanti, Rohmi Handayani \\ Kementerian Kesehatan Politeknik Kesehatan Surakarta Jurusan Kebidanan
}

\begin{abstract}
Oxytocin Massage, Breastfeedingadequacy. Factors that can increase breast milk production include frequency of breastfeeding, nutrition, rest and sleep patterns, psychological, and breastfeeding and breast care techniques. Breast care is useful in stimulating the breast, which affects the pituitary to release the hormone prolactin and oxytocin. This oxytocin massage is done to stimulate the reflex oxytocin or reflex let down. The goals of thisreasearchisto know the relationship of oxytocin massage to breast milk sufficiency in the Working Area of Karangdowo Public Health Center. This research is quantitative research by using preexperimental research design with Post test type only with control design. The population of this research was all postpartum day 1-3 in Working Area of Public Health Center Karangdowo from May until June 2017. Technique sampling used accidental sampling and technique of data analysis used Chi Square. Results of this reasearch are characteristics of mothers covering the age of 20-35 years, education, namely junior high and high school, the work of housewives and parity is multiparous. There is a relationship between breastfeeding adhequacy to postpartum mother who given oxytocin massage and which is not given oxytocin massage in Working Area of Karangdowo Klaten Public Health Center with.
\end{abstract}

Keywords: Oxytocin Massage, Breastfeedingadequacy

Abstrak: PijatOksitosin, Kecukupan ASI. Faktor-faktor yang dapat meningkatkan produksi ASI diantaranya meliputi frekuensi menyusui, nutrisi, pola istirahat dan tidur, psikologis, dan teknik menyusui dan perawatan payudara. Perawatan payudara bermanfaat merangsang payudara sehingga memengaruhi hipofise untuk mengeluarkan hormon prolaktin dan oksitosin. Pijat oksitosin ini dilakukan untuk merangsang refleks oksitosin atau reflexletdown.Tujuan Penelitian ini adalah untuk mengetahui hubungan pijat oksitosin terhadap kecukupan ASI di Wilayah Kerja PuskesmasKarangdowo Klaten. Penelitian ini adalah penelitian kuantitatif dengan menggunakan rancangan penelitian preexperimental dengan jenis Post testonlywithcontroldesign. Populasi penelitian ini yaitu seluruh ibu nifas hari 1-3 di Wilayah Kerja PuskesmasKarangdowo pada bulan Mei sampai dengan Juni 2017. Teknik sampling accidental sampling dan analisa data menggunakan chisquare. Hasil Penelitian ini diantaranya adalah karakteristik ibu yang meliputi umur yaitu 20-35 tahun, pendidikan yaitu SMP dan SMA, pekerjaan yaitu ibu rumah tangga dan paritas adalah multipara. Kesimpulan dari penelitian adalah ada hubungan kecukupan ASI pada ibu nifas yang diberi pijatan oksitosin dan yang tidak diberi pijatan oksitosin di Wilayah Kerja PuskesmasKarangdowo Klaten.

Kata Kunci. PijatOksitosin, Kecukupan ASI 


\section{PENDAHULUAN}

Air Susu Ibu (ASI) eksklusif adalah pemberian air susu ibu saja kepada bayi selama enam bulan pertama kehidupan bayi tanpa memberikan makanan atau cairan lain, kecuali vitamin, mineral, dan obat yang telah diizinkan (WHO, 2010). ASI eksklusif adalah pemberian ASI secara eksklusif pada bayi sejak lahir hingga bayi berumur enam bulan dan dianjurkan dilanjutkan sampai anak berusia 2 tahun.

Manfaat pemberian ASI terutama ASI Eksklusif untuk bayi sangat luar biasa, yaitu melindungi bayi dari berbagai penyakit seperti diare dan infeksi saluran pernafasan akut (Kementerian Kesehatan RI, 2010). Keadaan ini membuat Angka Kematian Bayi (AKB) lebih rendah daripada bayi yang tidak diberi ASI eksklusif. Berdasarkan hasil Survei Penduduk Antar Sensus (SUPAS) tahun 2015, Angka Kematian Bayi (AKB) di Indonesia mencapai 22 per 1000 kelahiran hidup dan Angka Kematian Balita (AKBA) mencapai 26 per 1000 kelahiran hidup, meski mengalami penurunan dari tahun sebelumnya, jumlah tersebut masih terbilang cukup tinggi.

Upaya yang dilakukan untuk memperbanyak produksi ASI menurut Prasetyo (2009) dalam Rahayu (2012)diantaranya meliputi frekuensi menyusui, nutrisi, pola istirahat dan tidur, psikologis, dan teknik menyusui dan perawatan payudara. Perawatan payudara bermanfaat merangsang payudara sehingga memengaruhi hipofise untuk mengeluarkan hormon prolaktin dan oksitosin. Pijat oksitosinini dilakukan untuk merangsang refleks oksitosinatau reflexletdown.

Pijat oksitosin adalah suatu cara pemijatan yang dilakukan pada ibu nifas untuk meningkatkan produksi hormon oksitosin. Pijat oksitosin dilakukan dengan memijat titik-titik tertentu dipunggung ibu. Pijat ini sangat bermanfaat untuk ibu nifas terutama untuk peningkatan kontraksi uterus saat nifas sehingga membantu proses involusi uterus dan memperlancar pengeluaran ASI ibu (Hardiyanti, 2010). Upaya yang dilakukan bidan sebagai penolong persalinan dalam upaya memperlancar produksi ASI dengan pijat oksitosin.

Hasil studi pendahuluan yang dilakukan di PuskesmasKarangdowo diketahui bahwa 4 dari 6 ibu kebingungan ketika bayi mereka menangis sedangkan ASI yang keluar belum lancar. Ibu bingung setelah menyusui bayi masih rewel. Mereka sempat bertanya mengenai cara agar ASInya berproduksi banyak. Ibu-ibu tersebut memiliki keinginan untuk memberikan ASI eksklusif pada bayi mereka. Informasi juga didapatkan dari petugas yang mengatakan bahwa sekitar $30 \%$ ibu mengeluh bahwa produksi ASI nyabelum mencukupi.

Berdasarkan latar belakang di atas maka penulis tertarik untuk melakukan penelitian tentang "Hubungan Pijat Oksitosin Terhadap Kecukupan ASI di Wilayah Kerja PuskesmasKarangdowo Klaten"

\section{METODE PENELITIAN}

Penelitian ini adalah penelitian kuantitatif dengan menggunakan rancangan penelitian preexperimental dengan jenis Post test only with control design. Populasi penelitian ini yaitu seluruh ibu nifas hari 1-3 di Wilayah Kerja Puskesmas Karangdowo pada bulan Mei sampai dengan Juni 2017.

Sampel penelitian ini yaitu ibu nifas hari ke 1-3 di wilayah kerja 
Puskesmas Karangdowo Klaten pada bulan Mei sampai Juni 2017. Sampel dalam penelitian ini akan diambil secara accidental sampling yaitu nonprobabilitas sampling teknik dimana subyek diambil secara kebetulan bertemu dengan peneliti dan sesuai dengan ciri-ciri atau karakteristik yang ditentukan oleh peneliti. Sampel dalam penelitian ini semua ibu yang melahirkan pada bulan Mei sampai dengan Juni 2017 di PKM Karangdowo Klaten sebanyak 36 orang.

\section{HASIL PENELITIAN}

\begin{tabular}{|c|c|c|}
\hline $\begin{array}{l}\text { Karakteristik Re } \\
\text { Distribusi Fre } \\
\text { wilayah Pus }\end{array}$ & $\begin{array}{l}\text { ponden } \\
\text { Tabel } 1 \\
\text { zuensi Kal } \\
\text { kesmas Ka } \\
\text { Klaten }\end{array}$ & $\begin{array}{l}\text { eristik d } \\
\text { gdowo }\end{array}$ \\
\hline Karakteristik & Frekuensi & $(\%)$ \\
\hline Umur & & \\
\hline$<20$ tahun & 2 & 5,6 \\
\hline $20-35$ tahun & 32 & 88,8 \\
\hline$>35$ tahun & 2 & 5,6 \\
\hline Pendidikan & & \\
\hline SD & 0 & 0,0 \\
\hline SMP & 18 & 50,0 \\
\hline SMA & 18 & 50,0 \\
\hline PT & 0 & 0,0 \\
\hline Pekerjaan & & \\
\hline IRT & 25 & 69,4 \\
\hline Swasta & 11 & 30,6 \\
\hline Buruh & 0 & 0.0 \\
\hline Paritas & & \\
\hline Primipara & 17 & 47,2 \\
\hline Multipara & 19 & 52,8 \\
\hline Jumlah & 36 & 100,0 \\
\hline
\end{tabular}

Berdasarkan tabel 1 sebagian besar responden $(88,8 \%)$ berusia $20-35$ tahun. Hasil ini sesuai dengan teori Wiknjosastro (2010), yang mengatakan bahwa umur 2035 tahun merupakan umur produktif. Berdasarkan teori Wiknjosastro (2010) yang menyatakan bahwa umur 20-35 tahun merupakan umur yang yang cukup dewasa dan bertanggung jawab, sehingga ibu yang melahirkan pada usia tersebut akan berupaya secara aktif untuk dapat meningkatkan produksi ASI agar dapat menyusui secara eksklusif (Soetjiningsih, 2010).

Responden berpendidikan SMP dan SMA, hal ini menunjukkan bahwa responden dalam penelitian ini telah mengikuti pendidikan formal. Pendidikan adalah usaha untuk meningkatkan pengetahuan, sehingga dapat meningkatkan pemahaman dan merubah perilaku seseorang (Notoatmodjo, 2010). Berdasarkan teori tersebut responden dalam penelitian ini dengan pendidikan menengah diharapkan lebih aktif mencari informasi termasuk tentang upaya meningkatkan produksi ASI.

Responden dalam penelitian ini sebagian besar adalah ibu rumah tangga, hal ini menunjukan bahwa responden memiliki banyak waktu maka ibu lebih sering menyusui bayinya sehingga produksi ASI lebih banyak.

Paritas responden sebagian besar adalah multipara, hal ini menunjukkan responden telah memiliki lebih dari 1 anak. Pengalaman ibu dapat meningkatkan informasi tentang upaya produksi ASI, sehingga semakin tinggi paritas semakin baik ibu dalam memberikan ASI, sehingga berusaha untuk meningkatkan produksi ASI (Hardiyanti, 2010). Ibu yang melahirkan lebih dari satu kali, produksi ASI pada hari keempat setelah melahirkan lebih tinggi dibanding ibu yang melahirkan pertama kali (Zuppa et al, 2011), meskipun secara statistik tidak terdapat hubungan nyata antara paritas dengan intik ASI oleh bayi pada ibu yang gizi baik. 
a. Pijat Oksitosin

Pijat oksitosin diukur dengan hasil dipijat dan tidak dipijat. Distribusi pijat oksitosin dapat diklasifikasikan sebagai berikut :

\section{Tabel 2}

Distribusi Frekuensi Pijat Oksitosin di Wilayah Puskesmas Karangdowo

\section{Kabupaten Klaten}

\begin{tabular}{|c|c|c|c|}
\hline No & Pijat Oksitosin & Frekuensi & $(\%)$ \\
\hline 1 & Dipijat & 25 & 69,4 \\
\hline 2 & Tidak Dipijat & 11 & 30,6 \\
\hline & Jumlah & 36 & 100,0 \\
\hline
\end{tabular}

bahwa sebanyak 25 responden $(69,4 \%)$ telah dilakukan pijat oksitosin. Pijat oksitosin adalah suatu cara pemijatan yang dilakukan pada ibu nifas untuk meningkatkan produksi hormon oksitosin. Pemijatan yang dilakukan disepanjang tulang belakang untuk merangsang hormon oksitosin dan prolaktin, sesuai dengan prosedur yang dilakukan selama 15 menit pada hari 1-3 masa nifas yang dilakukan 3 kali Pijat oksitosin dilakukan dengan memijat titik-titik tertentu dipunggung ibu. Pijat ini sangat bermanfaat untuk ibu nifas terutama untuk peningkatan kontraksi uterus saat nifas sehingga membantu proses involusi uterus yang memacu pengeluaran hormon oksitosin yang dapat juga memacu pengeluaran hormon prolaktin sehingga memperlancar pengeluaran ASI ibu (Hardiyanti, 2010).

\section{b. Kecukupan ASI}

Kecukupan ASI dapat dilihat pada tabel 3 dibawah ini

\section{Tabel 3}

Distribusi Frekuensi Kecukupan ASI

\begin{tabular}{llll}
\hline No & Kecukupan ASI & Frekuensi & $\mathbf{( \% )}$ \\
\hline 1 & Cukup & 26 & 72,2 \\
2 & Tidak Cukup & 10 & 27,8 \\
\hline & Jumlah & 36 & 100,0 \\
\hline
\end{tabular}

Berdasarkan hasil penelitian sebanyak 26 responden dengan ASI cukup. ASI adalah nutrisi bagi bayi yang dapat memenuhi kebutuhan gizi bayi dan melindunginya dalam melawan kemungkinan serangan penyakit. Keseimbangan zat gizi dalam air susu ibu berada pada tingkat terbaik dan air susunya memiliki bentuk paling baik bagi tubuh bayi yang masih muda. Pada saat yang sama ASI juga sangat kaya akan sari makanan yang mempercepat pertumbuhan sel otak dan perkembangan sistem saraf (Yahya, 2007).

\section{c. Hubungan Pijat Oksitosin Dengan}

Kecukupan ASI

Di bawah ini disajikan data hubungan pijat oksitosin dan kecukupan ASI dengan tabel silang sebagai berikut:

\section{Tabel 4}

Tabel Silang antara Pijat Oksitosin dengan Kecukupan ASI di Wilayah Puskesmas Karangdowo Kabupaten

\begin{tabular}{|c|c|c|c|c|c|c|c|c|}
\hline \multirow{3}{*}{ Pijat } & \multicolumn{4}{|c|}{ Kecukupan } & \multicolumn{2}{|c|}{ Total } & \multirow[t]{3}{*}{$\chi^{2}$} & \multirow[t]{3}{*}{$\mathrm{p}$} \\
\hline & \multicolumn{2}{|c|}{ Cukup } & \multicolumn{2}{|c|}{$\begin{array}{l}\text { Tidak } \\
\text { Cukup }\end{array}$} & \multirow[t]{2}{*}{$\mathrm{f}$} & \multirow[t]{2}{*}{$\%$} & & \\
\hline & $\mathrm{f}$ & $\%$ & $\mathrm{f}$ & $\%$ & & & & \\
\hline Pijat & 24 & 66,7 & 1 & 2,8 & 25 & 69,4 & 23,05 & 0,00 \\
\hline $\begin{array}{l}\text { Tidak } \\
\text { Dipijat }\end{array}$ & 2 & 5,6 & 9 & 25 & 11 & 30,6 & 8 & 0 \\
\hline Jumlah & 26 & 72,2 & 10 & 27,8 & 36 & 100 & & \\
\hline
\end{tabular}

Berdasarkan tabel di atas diketahui bahwa sebanyak 36 orang yang dipijat oksitosin sebanyak 25 orang dengan kecukupan ASI termasuk cukup sebanyak 24 orang $(66,7 \%)$ dan tidak cukup sebanyak 1 orang $(2,8 \%)$. Sedangkan responden yang tidak dipijat sebanyak 11 orang dengan cukup ASI sebanyak 2 orang $(5,6 \%)$ dan tidak cukup sebanyak 9 orang $(25 \%)$.

Berdasarkan hasil uji statistik dengan chi square didapatkan nilai nilai $\mathrm{p}$ $=0,000(\alpha<0,05)$, jadi ada hubungan pijat oksitosin terhadap kecukupan ASI di 
Wilayah Kerja Puskesmas Karangdowo Klaten. Hasil ini menunjukkan bahwa Ha diterima dan Ho ditolak sehingga ada hubungan yang signifikan antara pijat oksitosin dengan kecukupan ASI. Nilai $\chi^{2}$ $=23,058$ dan $p=0,000(\alpha<0,05)$. Hal ini berarti ibu-ibu yang mendapatkan pijat oksitosin akan berdampak pada kecukupan ASI lebih terpenuhi.

Penelitian Zamzara (2015) dengan hasil bahwa ada pengaruh Pijat Oksitosin Terhadap Waktu Pengeluaran Kolostrum Ibu Post Partum Sectio Caesar. Pijat oksitosin dilakukan untuk merangsang reflek hormon oksitosin atau let down reflek dengan adanya pijat oksitosin pada punggung sepanjang kedua sisi tulang belakang akan membuat ibu mersa rileks dan menghilangkan kelelahan. Ibu merasa rileks dan tenang akan memproduksi hormon oksitosin yang lebih banyak. Meningkatnya pengeluaran hormon oksitosin akan diimbangi dengan meningkatnya hormon prolaktin, kedua hormon tersebut akan merangsang kerja sel-sel alveoli dalam payudara untuk berkontraksi sehingga produksi ASI semakin meningkat (Hardiyanti, 2010).

Hasil penelitian ibu post partum yang dilakukan pijat bayi hanya 1 orang yang tidak lancar dalam pengeluaran ASI. Hal ini dikarenakan faktor psikologis dan dukungan keluarga yang kurang, karena anak tidak diinginkan. Menurut Sitti Saleha (2009) Pelepasan ASI berada dibawah kendali neuro-endokrin yang mana terjadi bila ada rangsangan sentuhan serta kenyamanan tubuh dan ketenangan pikiran ibu. Untuk menimbulkan kenyamanan ibu salah satunya dengan cara pijat oksitosin yaitu pemijatan sepanjang tulang belakang untuk membuat ibu nyaman dan pikiran rileks. Saat tubuh dan pikiran nyaman atau rileks maka hipotalamus dengan mudah melepaskan "rem" penahan oksitosin kemudian memerintahkan kelenjar hipofisis posterior mengeluarkan hormone oksitosin. Oksitosin yang dihasilkan oleh kelenjar hipofisis merangsang kelenjarkelenjar susu, mengencangkan otot halus disekitar alveoli. Oksitosin sampai pada alveoli menyebabkan kontraksi sel-sel (sel myioepithel) yang mengelilingi alveolus mamae dan ductus lactiferous. Kontraksi tersebut akan memeras air susu yang telah terbuat keluar dari alveoli dan masuk ke system dukstus yang untuk selanjutnya mengalir melalui duktus laktiferus menuju sinus lactiferous sehingga ASI keluar atau mengalir.

Berdasarkan hasil uji statistik dengan chi square didapatkan nilai nilai $\mathrm{p}$ $=0,000(\alpha<0,05)$, jadi ada hubungan pijat oksitosin terhadap kecukupan ASI di Wilayah Kerja Puskesmas Karangdowo Klaten

\section{KESIMPULAN DAN SARAN}

Berdasarkan hasil analisis dan pembahasan yang telah diuraikan pada bab sebelumnya, dapat ditarik kesimpulan sebagai berikut :

1. Karakteristik ibu sebagian besar yang meliputi umur yaitu 20-35 tahun, pendidikan yaitu SMP dan SMA, pekerjaan yaitu ibu rumah tangga dan paritas adalah multipara.

2. Kecukupan ASI pada ibu nifas yang dipijat oksitosin di Wilayah Kerja Puskesmas Karangdowo Klaten sebanyak 24 orang $(66,7 \%)$ dan tidak cukup sebanyak1 orang ( $2,8 \%$ )

3. Kecukupan ASI pada bayi dengan ibu yang dipijat oksitosin di Wilayah Kerja Puskesmas 
Karangdowo Klaten sebagian besar adalah tidak cukup 9 orang $(25 \%)$ dan cukup sebanyak 2 orang $(5,6 \%)$.

4. Ada hubungan kecukupan ASI pada ibu nifas yang diberi pijatan oksitosin dan yang tidak diberi pijatan oksitosin di Wilayah Kerja Puskesmas Karangdowo Klaten.

\section{SARAN}

1. Bagi Ibu Menyusui

Hasil penelitian ini diharapkan menambah pengetahuan ibu menyusui/keluarga tentang caracara pijat oksitosin untuk memenuhi kecukupan ASI pada bayinya.

2. Bagi Bidan

Dengan hasil ini diharapkan Bidan mampu meningkatkan KIE tentang upaya peningkatan produksi ASI melalui pijat oksitosin.

\section{DAFTAR RUJUKAN}

Departemen Kesehatan RI, Angka Kematian Ibu. Jakarta, 2010.

Hardiyanti, E.A, 2010. Indikator Perbaikan Kesehatan Lingkungan Anak (WHO). Jakarta: Penerbit Buku Kedokteran ECG

Haryono R, Setianingsih, S. 2014. Manfaat Asi Eksklusif Untuk Buah Hati Anda. Yogyakarta: Gosyen Publising.

Hubertin S. (2003). Konsep penerapan ASI eksklusif: buku saku untuk bidan. Jakarta: EGC.

Khomsan, ali.2010. Teknik Pengukuran Pengetahuan Gizi. Fakultas pertanian IPB

Latifah (2015) Perbandingan breast care dan pijat oksitosin terhadap produksi asi pada ibu post partum normal di Ruang Nifas RSUD Ratu Zalecha Martapura. Skripsi. USU

Notoatmodjo. 2012. Metodelogi Penelitian Kesehatan. Jakarta : Rineka Cipta

Proverawati, 2010. Kapita Selekta ASI \& Menyusui, Penerbit Nuha Medika, Yogyakarta

Rahayu L.S., 2012. Hubungan Tinggi Badan Orang Tua dengan Perubahan Status Stunting dari Usia 6-12 Bulan ke Usia 3-4 tahun. [tesis]. Yogyakarta: Universitas Gadjah Mada

Roesli, Utami. 2009. Mengenal ASI eksklusif. Jakarta: Trubus Agriwidya, Anggota IKAPI

Saleha, S. 2009. Asuhan Kebidanan pada Masa Nifas. Jakarta: Salemba Medika

Suherni, dkk, 2008.Perawatan Masa Nifas. Yogyakarta : Fitramaya

Sulistyawati. 2009. Buku Ajar Asuhan Kebidanan Pada Ibu Nifas. Yogyakarta: Andi

Widiyanti (2014) tentang Perbedaan antara dilakukan pijatan oksitosin dan tidak dilakukan pijatan terhadap Pengeluaran ASI di BPM Harini Delanggu Klaten

World Health Organization, United Nations Children's Fund. 2010. Globalstrategy for infant and young child feeding. Geneva, Switzerland: World Health Organization

Yahya. 2007. Cairan Ajaib Air Susu Ibu, Jakarta.Medika

Zamzara (2015) Pengaruh Pijat Oksitosin Terhadap Waktu Pengeluaran Kolostrum Ibu Post Partum Sectio Caesar. Skripsi. Yogyakarta 